Ensaio

Carlos Eduardo Carrusca Vieira ${ }^{1}$

Francisco de Paula Antunes Lima²

Maria Elizabeth Antunes Lima ${ }^{3}$

\section{E se o assédio não fosse moral? Perspectivas de análise de conflitos interpessoais em situações de trabalho}

\author{
What if bullying at work wasn't moral? \\ Interpersonal conflict analysis in working situations
}

\begin{abstract}
${ }^{1}$ Doutorando e mestre em Psicologia pela Universidade Federal de Minas Gerais. Professor do Departamento de Psicologia da Pontifícia Universidade Católica de Minas Gerais, Belo Horizonte, MG, Brasil.

${ }^{2}$ Pós-doutor em Ergologia pela Université de Provence. Professor Associado II da Universidade Federal de Minas Gerais, Belo Horizonte, MG, Brasil.

${ }^{3}$ Pós-doutoranda em Clínica da Atividade no Conservatoire National des Arts et Métiers (França). Doutora em Sociologia do Trabalho pela Université de Paris IX. Professora Associada na Universidade Federal de Minas Gerais, Belo Horizonte, MG, Brasil.
\end{abstract}

Contato:

Carlos Eduardo Carrusca Vieira

E-mail:

carloseduardo_carrusca@yahoo.com.br

O presente trabalho não foi subvencionado, não se baseia em tese nem foi apresentado em reunião científica.

\section{Resumo}

O debate em torno do assédio moral no trabalho intensificou-se ao final do século XX na Europa, a partir dos estudos de Heinz Leyman, na Suécia, e de Marie-France Hirigoyen, na França. Nesse debate, tem-se preocupado em conceituar o assédio moral, identificar suas causas, formas de manifestação e repercussões na saúde dos assalariados. Entretanto, as discussões em torno dos fatores que o determinam nem sempre são convergentes, deixando dúvidas quanto a suas verdadeiras causas, bem como às formas adequadas de se lidar com esse problema. No presente ensaio, apoiando-nos em pesquisas previamente realizadas junto à categoria dos vigilantes, discutimos de forma crítica as perspectivas tradicionais utilizadas para se estudar o assédio moral e as propostas mais comuns sugeridas para o enfrentamento desse problema, evidenciando suas limitações ao explicá-lo essencialmente como um fenômeno de natureza moral ou psicológica. Ao contrário, propomos analisá-lo por meio de outras abordagens fundadas no próprio trabalho que destacam a perversidade dos modelos contemporâneos de gestão.

Palavras-chave: assédio moral; psicologia do trabalho; conflitos no trabalho; saúde mental e trabalho; ergonomia da atividade.

\section{Abstract}

Discussion on bullying at work intensified in Europe in the late 20th Century, after studies carried out by Heinz Leyman, in Sweden, and by Marie-France Hirigoyen, in France. They were focused on conceptualizing bullying at work, identifying its causes, usual occurrence patterns, and its effects on workers' health. However, the debates have not converged on determinant factors of bullying at work, and doubt still remains over its real causes and the right way to confront it. In this essay, which empirical basis was derived from previous studies on security guards, we critically discuss the perspectives traditionally adopted when bullying at work is analyzed, and the most common proposals in facing it. We also point to their limitations, when bullying at work is explained essentially as an event of a moral and psychological nature. Opposed to these common proposals, we suggest adopting approaches which are grounded on work, and which evidence the perversity of the current management patterns.

Keywords: bullying at work; work psychology; workplace conflict; mental health and work; activity ergonomics. 


\section{Introdução}

O debate em torno do assédio moral nos contextos de trabalho intensificou-se ao final do século XX na Europa, a partir dos estudos de Heinz Leymann, na Suécia, e sobretudo de Marie-France Hirigoyen ${ }^{4}$, na França (FRONTZEK, 2009). No Brasil, a discussão foi desencadeada com a tradução do livro de Hirigoyen, Assédio moral: a violência perversa no cotidiano (2000), e a publicação da obra Violência, saúde, trabalho: uma jornada de humilhações, fruto da dissertação de mestrado da médica Margarida Barreto (2003). A partir desse momento, houve um crescente interesse pelo estudo dessa temática, evidenciado pelo aumento considerável do número de publicações acerca do assunto (FREITAS, 2001; GUEDES, 2003; AGUIAR, 2006; GUIMARÃES; RIMOLI, 2006; VIEIRA, 2008; FREITAS; HELOANI; BARRETO, 2008; SOBOLL, 2008; TROMBETA; ZANELLI, 2010).

Desde que o debate se instaurou, os pesquisadores têm se preocupado em conceituar o assédio moral, identificar suas causas, formas de manifestação e repercussões na saúde dos assalariados. Na literatura sobre o assunto é geralmente descrito como uma violência de natureza simbólica, repetida de forma sistemática e que atinge seriamente a saúde mental dos trabalhadores. ${ }^{5}$ Além disso, existe um consenso de que esse fenômeno pode se manifestar de várias maneiras, desde a exigência de tarefas "impossíveis" até o isolamento do indivíduo ou sua exposição ao ridículo. Entretanto, quando se discutem os fatores que o determinam, as posições teóricas nem sempre são convergentes, deixando dúvidas sobre suas causas, bem como sobre as formas adequadas de se lidar com o problema.

As explicações a respeito do assunto têm apresentado dois vieses típicos: 1) a tendência à psicologização dos conflitos interpessoais no trabalho; e 2) a judicialização desses conflitos. ${ }^{6} \mathrm{~A}$ origem fundamental dessas concepções é o pressuposto de que o assédio em questão é de natureza moral, tratando-se, portanto, de relações entre pessoas cujos eventuais danos podem ser objeto de reparação judicial. Mas, e se o assédio moral não fosse estritamente moral? Esta pergunta pode parecer absurda, mas apenas para quem aceita como dado o pressuposto que se cristalizou na denominação usual. Sem negar que os fenômenos designados (por exemplo, o abuso de poder, a violência verbal, a humilhação sistemática e os constrangimentos públicos) sejam reais, neste ensaio discutimos de forma crítica as perspectivas tradicionalmente utilizadas para se estudar esse problema e as propostas mais comuns sugeridas para seu enfrentamento, evidenciando suas limitações e sugerindo outra abordagem fundada no trabalho.

Em um primeiro momento, faremos uma breve exposição da forma tradicional de abordar a questão, bem como de suas limitações, em especial no que concerne às suas estratégias para lidar com suas consequências. ${ }^{7}$ Em seguida, com o respaldo da análise de situações de assédio moral na categoria dos profissionais da vigilância, exporemos

${ }^{4}$ HIRIGOYEN, M.-F. Le harcèlement moral: la violence perverse au quotidien. Paris: Syros, 1998. (Obra publicada originalmente na França e amplamente difundida em vários países).

${ }^{5}$ Na definição de Hirigoyen (2000), por “assédio em um local de trabalho temos que entender toda e qualquer conduta abusiva manifestando-se, sobretudo, por comportamentos, palavras, atos, gestos, escritos que possam trazer dano à personalidade, à dignidade ou à integridade física ou psíquica de uma pessoa, pôr em perigo seu emprego ou degradar o ambiente de trabalho" (p. 65).

${ }^{6}$ O termo "viés" se justifica neste caso, uma vez que não estamos nos referindo apenas a mais uma forma de abordar o problema entre tantas outras, mas sim a uma maneira tendenciosa de abordá-lo, segundo a qual um aspecto é exacerbado em detrimento de outros que, em alguns casos, sequer são considerados, embora, inegavelmente, façam parte do fenômeno. O que caracteriza o viés na questão do assédio moral no trabalho é que o próprio trabalho não assume papel determinante em algumas análises. Assim, não estamos criticando as abordagens da psicologia e do direito enquanto tais, mas sim os vieses presentes em autores que generalizam a análise do assédio moral no trabalho a partir dessas disciplinas. O viés se caracteriza quando análises pertinentes em contextos sociais ou casos específicos ultrapassam seus limites de validade. O erro, a nosso ver, não consiste em uma representação falsa da realidade, mas na extrapolação indevida de uma verdade parcial, por exemplo, quando se atribui de forma errônea certas relações causais a fenômenos aparentes. Normalmente, a descrição fenomenológica não é falsa, como acontece no caso das práticas do assédio, mas sim sua explicação em termos de traços de personalidade. Caracterizaremos esse viés no decorrer deste ensaio, a partir das obras principais de Marie-France Hirigoyen, a autora que teve uma importância maior no desencadeamento dessa discussão no Brasil.

${ }^{7}$ As teses de Marie-France Hirigoyen foram privilegiadas no artigo em detrimento daquelas propostas por Leymann. Isso se justifica em função da ampla difusão das obras da primeira autora em nosso país e da incorporação de seu viés no tratamento da questão nos âmbitos acadêmico e jurídico (cf. TEIXEIRA, 2011; ZIMMERMAM; SANTOS; LIMA, 2011). É relevante destacar que a abordagem psicossocial que cunhou o conceito de assédio organizacional não constitui objeto desta análise, porque, a nosso ver, não incorre nos problemas específicos da abordagem tradicional que serão indicados neste ensaio. Ao contrário, Soboll (2008) identifica de modo pertinente que não são apenas as características individuais as responsáveis pela determinação da violência nas organizações. A autora destaca que, salvo raras exceções, as atitudes abusivas encontram suas raízes na própria organização do trabalho, sendo um reducionismo tratar o assédio do ponto de vista individual. Essa parece ser também a perspectiva adotada por Freitas, Heloani e Barreto (2008) quando afirmam ser “[...] preciso buscar no contexto social e organizacional mais amplo as raízes de um fenômeno que se expressa na interação de pessoas no cotidiano do trabalho, mas que não se confunde com uma prática resultante meramente de conflitos pessoais ou antipatias aleatórias" (p. 16). 
nossa perspectiva acerca dos fatores determinantes do assédio moral e das formas mais efetivas para combatê-lo.

\section{As perspectivas tradicionais de análise do assédio moral}

Conforme dissemos, a discussão sobre o assédio moral foi introduzida por Heinz Leymann (1990, 1993, 1996), baseada nos estudos que realizou na Suécia durante os anos de 1980. O mobbing (ou psicoterror), como foi denominado esse fenômeno pelo autor, caracterizar-se-ia por uma "comunicação hostil e desprovida de ética perpetrada de modo sistemático por um ou mais indivíduos contra um único indivíduo" (LEYMANN, 1990, p. 120). O termo mobbing foi emprestado de Konrad Lorenz, um etólogo austríaco que o utilizou para designar o ataque de um grupo de pequenos animais gregários a um animal solitário (LEYMANN, 1996).

Em seguida, o conceito de assédio moral foi largamente difundido a partir das produções de Marie-France Hirigoyen na França, no final dos anos 1990. Ressalvadas as diferenças entre as proposições desses pioneiros, ambos têm em comum a visão de que se trata de um comportamento destrutivo e antiético, de caráter repetitivo e sistemático, capaz de afetar a saúde mental dos indivíduos assediados.

No caso específico de Marie-France Hirigoyen (2000, 2002), em que pese a importância da contribuição dessa autora no sentido de alertar para o problema - levando pesquisadores, trabalhadores e seus representantes a se debruçarem sobre ele -, não podemos negligenciar o fato de que suas análises foram parciais e tendenciosas, sob pena de estagnar a compreensão desse grave problema social. No entanto, apesar dos seus limites, a forte influência que exerceram nas reflexões em torno do assunto nos parece inegável e é sobre isso que gostaríamos de tecer algumas considerações.

Em primeiro lugar, aqueles que aderem à perspectiva dessa autora consideram que a primazia entre os fatores determinantes do fenômeno seria de ordem psicológica. O assédio moral é, nesse caso, caracterizado como uma "perseguição deliberada", em última instância explicável por aspectos estritamente individuais (TEIXEIRA, 2011; ZIMMERMANN; SANTOS; LIMA, 2011).

Assim, quando se trata de investigar as determinações do assédio moral, pode-se dizer que é frequente a tentativa de analisar o fenômeno em uma perspectiva estritamente psicológica, segundo a qual os conflitos no âmbito de relações interpessoais seriam provocados por uma espécie de "choque de personalidades", ou seja, são as diferenças e os atributos individuais que estariam na sua origem. Por isso, tenta-se, com certa frequência, caracterizar o perfil psicológico dos assediadores e dos assediados, sendo os primeiros quase sempre taxados como perversos e os segundos como frágeis e indefesos. Isso pode ser ilustrado por uma passagem de Hirigoyen (2000), na qual a autora define a violência moral no trabalho como uma conduta intencional e deliberada de "perversos narcisistas" ou, nos seus próprios termos: "Uma vez escolhida a presa, o perverso não a larga mais. E é frequente que ele o declare abertamente: de agora em diante, meu único objetivo na vida será impedi-la de viver" (HIRIGOYEN, 2000, p. 135).

É claro que não nos escapa o fato de que, eventualmente, possam existir nesses contextos comportamentos deliberadamente perversos e destrutivos. Não negamos que a perversão exista na sociedade em geral, inclusive no trabalho. O que criticamos é a ideia de que tais comportamentos seriam os únicos capazes de explicar o assédio moral ou mesmo que seriam predominantes, concepção presente nas duas obras principais de Marie-France Hirigoyen $(2000,2002)$. Por acreditar que as origens do assédio moral repousam sobretudo na personalidade individual, a autora relaciona sua ocorrência à pressuposição de que os "perversos narcisistas" têm ocupado "postos estratégicos" nas empresas por meio de "uma espécie de seleção natural" (HIRIGOYEN, 2002, p. 281). Para ela, o mundo do trabalho é "cada vez mais implacável" e, assim, os perversos, "por serem frios, calculistas e desprovidos de crises de consciência", seriam os indivíduos mais convenientes às empresas, em especial nos cargos estratégicos, pois "saberão privilegiar os elementos racionais sem se deixar comover com as suscetibilidades alheias" (p. 281). Ou seja, no fim das contas, não se trata fundamentalmente de uma reestruturação do mundo do trabalho que transforma as relações de trabalho e induz comportamentos ditos de "assédio" - ao criar situações de conflitos interpessoais e dramas profissionais -, mas sim de uma ocupação dos postos estratégicos por indivíduos que já são perversos antes mesmo de viverem essas situações.

Em geral, nesse tipo de análise, as questões relativas às formas de sociabilidade contemporânea, aos modos de gestão e organização do trabalho são desconsideradas ou apenas citadas como parte do contexto em que o assédio ocorre, sem que se estabeleçam as mediações necessárias entre eles e o problema examinado. A relação entre os chamados "conflitos interpessoais" e as contradições e os 
paradoxos existentes na organização do trabalho, nos modelos organizacionais e nas práticas de gestão, sequer chega a ser considerada ou é tratada apenas de forma pontual.

Assim, apesar de fazer menção a fatores relativos aos processos de gestão e organização do trabalho, Marie-France Hirigoyen sempre acaba concluindo que o assédio moral é determinado por problemas de ordem essencialmente individual e psicológica, sendo esse o aspecto que, a nosso ver, caracteriza o viés do seu pensamento. Mesmo em sua segunda obra, Mal-estar no trabalho - redefinindo o assédio moral (2002), na qual propõe uma ampliação de seus estudos acerca do tema, a autora deixa claro que o trabalho nada mais é que um dos ambientes onde a violência perversa se manifesta, concluindo que o assédio moral é uma ação deliberada e intencional, alimentada por características da personalidade do agressor:

Também se ouve dizer que as reestruturações são a fonte do assédio moral. Não são as reestruturações em si que criam o processo destruidor, mas sempre existirão pessoas com sede de poder que se aproveitarão de qualquer modificação ou de qualquer reorganização para subir na empresa. Elas contam com a confusão ou agitação reinantes para disfarçar suas ações perversas. (HIRIGOYEN, 2002, p. 65)

[...] no assédio moral, como em toda agressão, existe uma vontade de ferir o outro. O objetivo do assédio é controlar e dominar o oponente, usurpando seu território psíquico. Não se trata da descarga de agressividade de um indivíduo submetido a excesso de estresse ou a condições de trabalho adversas. Não é uma perda de autocontrole, mas, ao contrário, é uma vontade de dominar o outro. (HIRIGOYEN, 2002, p. 247)

A determinação do trabalho no fenômeno aqui analisado é expressamente recusada pela autora. Ao negar a influência dos modos de gestão nos atos dos indivíduos, ela reduz o contexto organizacional a um mero décor no qual se expressa a perversidade individual.

Outros autores, no entanto, entendem que a personalidade individual não é suficiente, de forma isolada, para explicar o assédio moral, não sendo sequer seu fator explicativo preponderante, considerando o modo de produção capitalista em geral e as formas específicas de gestão das empresas como elementos centrais na compreensão dessas condutas. Nesse caso, são mencionadas as formas de gestão e organização do trabalho como fatores associados ao assédio moral, mas não se elucida como eles se articulam, tampouco as razões pelas quais algumas pessoas expostas ao mesmo contexto não adotam tal prática. Ou seja, mesmo aqueles que levam em conta certos aspectos do trabalho também têm falhado ao cair em uma espécie de "sociologismo" que privile- gia os fatores sociais, desconsiderando aqueles de ordem pessoal.

Na sua obra $A$ gestão como doença social, Vincent de Gaulejac (2007) desenvolve uma análise atual e crítica dos novos modelos de gestão que colocam metas impossíveis e conseguem, apesar de tudo, mobilizar os trabalhadores, ainda que não lhes sejam dadas as condições de trabalho adequadas para melhorar o desempenho. Metas sempre crescentes, objetivos contraditórios, injunções paradoxais, responsabilização e individualização dos resultados constituem o pano de fundo do trabalho nas chamadas "organizações hipermodernas". Como bem percebido por esse autor, em termos teóricos, sob esses fenômenos viceja "uma concepção subjetivista da ação, a ideologia da realização de si mesmo, que transforma as contradições sociais em problemas relacionais" (GAULEJAC, 2007, p. 189).

Todavia, apesar dessa crítica aguda, o autor, ao abandonar a teoria do valor, resvala para uma perspectiva, em seus fundamentos últimos, de natureza moral. O abandono dos fundamentos da produção capitalista - o valor que se valoriza - tem um grande ônus. Isso acontece quando a produção de riqueza sob o capital é confundida com a produção de riqueza material, a produção de valor, com valores de uso:

Os remédios para a "doença da gestão" decorrem do
diagnóstico. Convém de início, pensar a gestão de
modo diferente, reinscrevendo-a em uma preocupa-
ção antropológica: uma gestão humana dos recursos,
mais que uma gestão dos recursos humanos. A crise
que atravessamos não é uma crise econômica, pois
nossas sociedades continuam a produzir a riqueza.
Ela é, antes de mais nada, uma crise simbólica, que
atinge as relações entre o econômico, o político e o
social. Em vez de gerar a sociedade para pô-la a ser-
viço do desenvolvimento econômico, convém pensar
uma economia a serviço do bem comum, lembrando,
conforme Marcel Mauss, que a ligação (ou vínculo, re-
lação) é melhor que o bem. (GAULEJAC, 2007, p. 146)

Cabe, no entanto, interrogar se seria possível adotar formas de gestão substancialmente diferentes uma vez que a produção continua orientada para a produção de valor. As metas em crescimento contínuo não nascem da vontade perversa de executivos e conselhos de administração, que apenas expressam a natureza insaciável do valor que se valoriza. Nesse sentido, a produção crescente de riqueza material agrava o problema, pois toda a riqueza acumulada se torna um pressuposto de um novo ciclo de valorização, um ponto de partida que requer mais aumentos de produtividade e assim indefinidamente. A contradição entre a imensa riqueza material acumulada e o trabalho morto que somente pode se reproduzir de forma ampliada sugando mais trabalho vivo torna a base dos novos ciclos de valorização cada vez mais estreita, o que, 
após vários desdobramentos, manifesta-se na pressão exercida sobre os trabalhadores para melhorar continuamente seu desempenho. ${ }^{8}$

Além disso, o pressuposto de que, por detrás das condutas dos agressores, haveria um propósito claro e deliberado de arruinar a vida da vítima tem promovido a transferência das tentativas de resolução do assédio moral para a esfera jurídica, o que evidencia outra tendência: a judicialização dessa questão. Nesse caso, acredita-se que esse problema só poderá ser resolvido no âmbito jurídico, gerando a procura de culpados, o que geralmente afasta a possibilidade de transformação da organização do trabalho, istoé, de tomar o problema em sua raiz.

Em um recente debate realizado na França, a questão do assédio moral foi discutida por três teóricos que apresentam reflexões importantes em torno dos problemas que tocam o mundo contemporâneo do trabalho: o psicólogo do trabalho Yves Clot, o economista Philippe Askenazy e a psicanalista e psiquiatra Marie-France Hirigoyen (HIRIGOYEN; ASKENAZY; CLOT, 2005). A posição assumida por esta última não diferiu substancialmente daquilo que expusemos acima. No entanto, as reflexões trazidas por Clot (2005) permitem abordar o tema de um modo mais adequado.

Em primeiro lugar, ele expressa seu incômodo pelo fato de as demandas em torno dos problemas de saúde no contexto de trabalho terem passado a ser traduzidas como "assédio moral". Afirma que a reformulação legal dos conflitos profissionais em conflitos pessoais pode levar a várias ilusões, dizendo que, ao colocar acento exclusivamente na relação entre dois indivíduos, o agressor e a vítima, essa discussão pode abrir caminho para a "criminalização das condutas mais do que para as transformações da organização do trabalho que as solicita" (CLOT, 2005, p. 7). Ele interroga de forma pertinente o alcance e a eficácia da judicialização dos conflitos no trabalho:

A regra ou o procedimento podem substituir de modo durável o trabalho comum de criação e recriação de uma história a transmitir e a retomar em todos os sentidos do termo? Eu escuto frequentemente dizerem sobre o assédio moral: "pelo menos agora se pode falar". Sem dúvida, mas isso ocorre também - não se pode esquecer - porque as forças de convocação dos coletivos de trabalho têm visto recuar seu poder de agir. (CLOT, 2005, p. 15)

Nesse sentido, Clot (2005) questiona se, de fato, a real função da psicologia seria a de oferecer a escuta nas organizações, levando as pessoas a mobilizarem cada vez mais seus recursos "para suportar o insuportável” (CLOT, 2005, p. 10). Ele manifesta, assim, sua descrença de "que nós (psicólogos) possamos, por muito tempo, nos satisfazer fazendo 'perfusões psicológicas' em um trabalho doente em seu modo de organização" (CLOT, 2005, p. 10) e constata que, cada vez mais, fala-se sobre a necessidade de se escutar os trabalhadores, mas sem procurar intervir no próprio trabalho (CLOT, 2005).

Contrapondo-se a uma perspectiva adotada pela Psicodinâmica do Trabalho, Clot (2005) afirma que a maior fonte de sofrimento dos trabalhadores se encontra na impossibilidade de se reconhecerem naquilo que fazem e não na ausência do reconhecimento de chefes ou colegas. O trabalho maltratado não deve ser reconhecido, mas transformado, afirma ele. Sua preocupação central consiste, portanto, em "restaurar a possibilidade de as pessoas se reconhecerem no trabalho que fazem" (CLOT, 2005, p. 10), pois muitos "doentes do trabalho se encontram entre os profissionais que não suportam mais que o seu ofício seja maltratado" (CLOT, 2005, p. 10). Na sua perspectiva, portanto, o que contribui para as querelas pessoais é a ausência de debates internos aos coletivos profissionais acerca de questões relativas ao próprio trabalho (CLOT, 2005). Evidentemente, Clot não ignora a importância do reconhecimento de chefes e colegas no que concerne à preservação da saúde mental. Ele propõe apenas uma mudança de ênfase quando tratamos do sofrimento no trabalho ao dizer que a impossibilidade de o trabalhador se reconhecer no que faz é mais difícil de suportar do que a ausência de reconhecimento dos pares ou da hierarquia, sendo que a presença da primeira forma de reconhecimento pode suprir em grande medida a ausência da segunda, enquanto a recíproca não é verdadeira.

\footnotetext{
${ }^{8}$ Por mais interessante que seja, não podemos aqui, desenvolver uma base conceitual para explicar o assédio a partir dos textos de Marx limitando-nos apenas a essas referências que, apesar de breves, parecem-nos essenciais para evidenciar determinações concretas desses fenômenos. Podemos, por exemplo, comparar a forma como Gaulejac (2007) considera a riqueza material na citação anterior, ao afirmar que não se trata de uma crise econômica, ao que Marx já dizia ao se perguntar: "quando despida de sua estreita forma burguesa, o que é a riqueza senão a totalidade das necessidades, capacidades, prazeres, forças produtivas, etc. dos indivíduos, adquirida no intercâmbio universal? O que é, senão o completo desenvolvimento do domínio humano sobre as forças naturais - tanto as suas próprias quanto as da chamada 'natureza'? O que é, senão a plena elaboração de suas faculdades criadoras, sem quaisquer precondições além da evolução histórica precedente que transforma num fim em si, a totalidade desta evolução - isto é, a evolução de todas as forças humanas, como tais, não medidas por nenhum critério previamente estabelecido?" (MARX, 1985, p. 80-81). Para que essa possibilidade se efetive, Marx não propõe que se "humanize a gestão", mas sim que a forma capital seja superada. Outra determinação essencial que diz respeito ao assédio concerne à relação entre violência e economia. A análise da acumulação originária em 0 Capital realizada em um capítulo à parte, pode levar a pensar que se trata apenas da pré-história do capital que recorre à violência enquanto os processos de exploração fundados nos mecanismos de extração da mais-valia relativa não são instituídos. No entanto, como argumenta Lukács (2010), a violência não é uma relação extraeconômica, mas uma determinação inerente às relações de produção capitalistas.
} 
Por tudo isso, acreditamos ser necessário superar as análises tradicionais do problema, sobretudo aquelas que negligenciam os fatores relativos ao trabalho. Assim, pode-se dizer que o "assédio moral no trabalho" é, antes de tudo, uma manifestação do "trabalho assediado", de uma atividade que não consegue se desenvolver face às contradições sociais que se materializam em determinadas formas de organização e nos modelos de gestão atuais. Ou seja, podemos entender o assédio moral, em sua forma atual, como uma manifestação particular das relações de poder e da violência entranhadas na economia e nos processos de produção. São conflitos intersubjetivos, com fortes cores pessoais, que, todavia, expressam contradições econômicas fundamentais entre capital e trabalho por meio de mediações que começamos a esboçar aqui. Sem dúvida, para sustentar essa afirmação é necessário apresentar evidências empíricas e análises concretas de como operam essas determinações gerais em situações de "assédio moral", sendo o caso apresentado a seguir um interessante ponto de partida.

\section{O caso do vigilante Ricardo $^{9}$ : atividade amputada, paradoxo e conflito}

Em um estudo sobre a saúde mental dos vigilantes bancários, Vieira $(2008,2009)$ analisou a trajetória ocupacional do vigilante bancário Ricardo, de 40 anos, a fim de identificar os fatores que determinaram o seu adoecimento. Esse trabalhador foi afastado de sua função por ter sido acometido do Transtorno de Estresse Pós-Traumático (TEPT) logo após um assalto à agência bancária onde trabalhava. Entretanto, como assinala Vieira (2009), o próprio trabalhador considerou determinante em seu processo de adoecimento a degradação das relações com os colegas de trabalho, o que, segundo ele, teria ocorrido após a introdução de novas normas de segurança:

$\mathrm{Eu}[\ldots]$ creio que eu esteja estressado mesmo. Essa doença minha foi causada pelo relacionamento dos funcionários, não pelo assalto. O assalto acabou de... foi a gota d'água, entendeu? (VIEIRA, 2009, p. 152)

Mas o que tornou a minha vida um inferno naquele setor (não só eu, mas também meus familiares e amigos). Foi quando implantou normas de segurança em agosto de 2002. Onde praticamente $90 \%$ dos funcionários não aceitou, ou seja, eles criaram uma forte resistência. Como eu estava lá para cumprir normas e, ao mesmo tempo, fazer cumprir, ou seja, colocar ordem na casa só que até hoje pago um preço muito alto, pois fui demasiadamente humilhado, isolado, ameaçado, ouvindo deboche de um e outro, sabotagem psicológica, ironia e sem levar em conta a discriminação que rola solta. (VIEIRA, 2009, p. 153)
No decorrer do estudo de caso, assiste-se a uma série de humilhações sofridas pelo vigilante. Ele era criticado sistematicamente pelos funcionários do banco por exigir obediência e respeito às novas normas de segurança, como ilustra a seguinte passagem:

Outro dia, eu estava dentro do quartinho lá embaixo, coincidência, eu cheguei lá embaixo pra pegar um negócio no quartinho que fica com a porta fechada próximo da garagem do banco; [...] Aí, de repente, chega um gerente lá: "Vou pôr esse crachá aqui, porque senão vai chegar lá em cima o Ricardo vai cobrar esse crachá. Aquele chato daquele Ricardo vai cobrar esse crachá e eu vou ter que mandar ele [...]" - falou assim. E eu lá dentro. Ele falou do meu lado. Diferença só que eu estava de um lado da porta e ele do outro. (VIEIRA, 2009, p. 153)

O conflito gestado na organização do trabalho se estendeu às relações interpessoais e logo foi associado unicamente ao comportamento do vigilante Ricardo, dando a impressão de que ele - e não as normas impostas - era o problema a ser enfrentado na agência bancária (VIEIRA, 2009).

Assim, ao tentar fazer respeitar as novas normas de segurança, o vigilante se viu na contingência de controlar a ação de funcionários e do público em geral dentro da agência bancária, o que acarretou sérios problemas para suas relações profissionais.

Os relatos do vigilante já ofereciam pistas de que a origem dos conflitos não poderia ser encontrada unicamente em sua personalidade: "[...] o que fazia com que as pessoas estavam me isolando era justamente o meu trabalho e não a minha pessoa. Era o meu trabalho e não a minha pessoa" (VIEIRA, 2008, p. 93). Contudo, segundo Vieira (2009), os conflitos continuaram a ser interpretados como resultado de sua postura, razão pela qual as humilhações persistiram, levando ao seu isolamento:

[...] se tornou muito difícil a partir desse momento
que eu fui... que o pessoal me isolou. Aí me isolaram!
Era piadinha, me chamavam de E. [...] Por que me
chamavam de E.?! Porque as normas vinham do setor
de segurança de São Paulo e o supervisor de segu-
rança em São Paulo é o E. E eles não gostavam do E.
Aí os caras falavam assim: "Esse E. não manda nada
não, esse E. é um bosta!". Então, eles falavam pra
mim isso: "E. é um bosta!" e me chamava de E. Eles
tavam me chamando de quê?! (VIEIRA, 2009, p. 154)

É comum que situações como essas sejam interpretadas sob um viés estritamente "psicológico e moral” (VIEIRA, 2009). Entretanto, a análise desse caso permitiu identificar que a conduta do vigilante não se justificava apenas por seus valores pessoais, construídos no decorrer de sua história de vida, ou pelo desejo de reconhecimento, mas também por

${ }^{9}$ Trata-se de um nome fictício. 
razões diretamente relacionadas à sua atividade, a saber: a) pela exigência profissional de cobrar dos funcionários obediência às novas normas; b) pelas vulnerabilidades que o próprio vigilante já havia identificado na agência bancária (VIEIRA, 2009).

Não se pode deixar de considerar que o vigilante chegou a apresentar aos gestores um relatório com sugestões para reforçar a segurança na agência bancária (VIEIRA, 2008). Entretanto, suas recomendações não foram consideradas, haja vista a cisão existente entre o planejamento e a execução do trabalho, que retira dos trabalhadores o poder de modificar a organização de sua atividade (VIEIRA, 2008).

É importante ressaltar, ainda, que Ricardo trabalhou nessa agência bancária durante mais de 10 anos sem nunca ter tido qualquer tipo de problema com os colegas de trabalho ou chefias. Ao contrário, ele chegou a dizer que era o "xodó do pessoal”, porque realizava suas tarefas com dedicação (VIEIRA, 2008). Entretanto, como se pode perceber, após a introdução de novas normas de segurança, em 2002, passou a ser alvo de deboches e a ser ridicularizado por exigir dos funcionários obediência às normas de segurança.

O caso de Ricardo, analisado em profundidade, mostra como características pessoais e profissionais (o apego às normas e às ordens dos superiores, o zelo pela segurança...) se transformam em fonte de conflitos no trabalho quando normas contraditórias são criadas. Quando se considera sua história de vida e sua trajetória profissional, pode-se concluir que as causas determinantes do assédio estão na própria situação de trabalho cujas mudanças desencadearam o processo que culminou no seu adoecimento. ${ }^{10}$

A contradição fundamental, nesse caso, consiste na dupla linha de comando a que se submete o vigilante terceirizado, responsável por fornecer uma segurança impossível com regras que entram em conflito com o funcionamento normal de uma agência, como denunciam as discussões recorrentes com empregados do banco e clientes. Não podendo servir a dois senhores, ele sofre agressões de um lado ou de outro, dependendo das escolhas que faz.

Assim, o vigilante Ricardo foi ridicularizado, sendo alvo de críticas e deboches por parte dos funcionários e gestores do banco durante mais de um ano, o que nos parece suficiente para concluir que se trata de um caso típico de assédio moral nos termos da literatura especializada. Se sua história de vida é sempre singular, as contradições que enfrenta nas situações de trabalho podem ser generalizadas, e o estudo mais amplo irá revelar, no entanto, que não se trata de um caso isolado, sendo o contexto de trabalho na vigilância bastante favorável ao surgimento desse tipo de problema.

\section{O caso dos vigilantes na Região Metro- politana de Belo Horizonte}

Em um diagnóstico mais abrangente sobre as condições de trabalho e saúde dos vigilantes na região metropolitana de Belo Horizonte (VIEIRA; LIMA; LIMA, 2010), realizado em parceria com o Sindicato dos Empregados de Empresas de Vigilância de Minas Gerais e com o Ministério Público do Trabalho (3a região), constatou-se que, dentre as várias dificuldades enfrentadas por esses trabalhadores em seu dia a dia, existem sérios problemas relacionados às práticas de gestão adotadas pelas empresas de vigilância, sendo o assédio moral frequentemente citado.

O estilo de gestão caracteriza-se, basicamente, por autoritarismo, controle excessivo e punições arbitrárias, sendo considerado pelos vigilantes como “punitivo”, “ameaçador”, “injusto”, envolvendo práticas como:

- transferência de setor e "pingue-pongue": sem aviso ou justificativa, os vigilantes são transferidos para postos de trabalho considerados "ruins" ou "condenados" à reserva; ${ }^{11}$

- advertências injustificadas: os "balões"12 e as advertências (verbais e/ou escritas) são práticas muitas vezes usadas de forma injustificada, pois, de acordo com os vigilantes, os superiores hierárquicos, de modo geral, não se dispõem a ouvir o ponto de vista dos trabalhadores ou "suas versões a respeito dos fatos", apressando-se logo em "registrar as ocorrências”. Em grande parte dos casos, essas advertências estão fundamentadas apenas no ponto de vista dos superiores ou em reclamações dos clientes, o que indica uma clara adesão à ideia de que "o cliente tem sempre razão". Contraditoriamente, em certas situações, é justamente o "cumprimento do dever" e das "normas pres-

\footnotetext{
${ }^{10}$ É claro que não se pode negligenciar a importância do assalto no transtorno apresentado por Ricardo, mas ele próprio atribuiu a esse fato uma importância secundária ao dizer que, no seu caso, “o estresse eu já tava, o trauma veio depois” (VIEIRA, 2008, p.), deixando claro que os conflitos vivenciados no seu contexto de trabalho prepararam o caminho para seu adoecimento.

${ }^{11}$ É quando o vigilante não possui um setor determinado de trabalho, ficando à disposição da empresa de vigilância para ser remanejado para qualquer setor, escala e turno de trabalho, de acordo com a necessidade das empresas contratantes.

${ }^{12} \mathrm{O}$ "balão" é forma de punição dos empregados mediante sua dispensa assim que chegam ao serviço e corte da remuneração do dia.
} 
critas" que gera a penalização do trabalhador, conforme ocorre em conflitos provocados pela porta giratória.

- ameaças de demissão são adotadas como recursos para controlar e punir os vigilantes, bem como para desmobilizar as greves da categoria. Segundo os trabalhadores, já houve casos de empresas que iniciaram o treinamento de outro contingente, ameaçando efetivá-lo no lugar dos trabalhadores que aderiram à greve, em estratégia de flagrante terror psicológico e ofensa ao direito de greve, conforme garante a Lei $\mathrm{n}^{\mathrm{o}}$ 7.783/89 (BRASIL, 1989).

- insultos, acusações, agressões verbais: os maus tratos dispensados pelos superiores hierárquicos aos vigilantes, por meio de ofensas verbais, expressões pejorativas e acusações, são comumente relatados.

- controle disciplinar rigoroso: vários vigilantes informaram que são obrigados a adotar certas "posturas" durante toda a jornada de trabalho. Além de permanecerem na posição de pé, em alguns casos, eles devem manter as mãos e os braços para trás, sendo fonte de dores musculares em variadas regiões do corpo, como ombros e costas. Muitos entendem que esse fato se deve, em parte, à "herança militar" daqueles que ocupam os cargos de supervisão das atividades dos vigilantes.

Algumas das condutas coercitivas citadas acima, praticadas de forma reiterada, caracterizam, conforme vimos acima, aquilo que se convencionou chamar de "assédio moral", uma forma de violência psicológica capaz de atingir gravemente a subjetividade e a saúde mental dos trabalhadores. Trata-se de uma prática que pode se manifestar de formas variadas, mais ou menos sutis, mas que implica sempre na exposição frequente dos trabalhadores a situações vexatórias e constrangedoras, acarretando sentimentos de menos-valia, insatisfação desânimo, indignação e afetando, com o passar do tempo, sua autoestima e saúde mental.

A propósito, ressalte-se que o próprio Ministério Público do Trabalho (MPT) já constatou a existência desse problema na área da vigilância, de modo que, em 2009, foi movida uma Ação Civil Pública (ACP) contra uma empresa de vigilância, baseada em de- núncias e depoimentos de vigilantes, na qual a procuradora arrolou várias práticas de gestão abusivas, sendo algumas citadas:

- dilatação constante e excessiva da jornada de trabalho;

- uso recorrente de advertências, ameaças de demissão e punições aos vigilantes (como, por exemplo, rebaixamento de posto, transferência de setor);

- exigências de tarefas extras e em tempo exíguo, muitas vezes incompatíveis com a função de vigilante;

- emprego de palavras e termos que desqualificam os trabalhadores;

- convocação dos vigilantes para o trabalho nos dias de folga;

- oferta de meios e instrumentos de trabalho em condições precárias;

- exacerbados monitoramento e vigilância dos trabalhadores;

- retaliação dos vigilantes que participam de movimentos grevistas. ${ }^{13}$

Na ACP, a procuradora do Ministério Público do Trabalho da 3a região, Advane de Souza Moreira, lembra que, apesar de não haver uma lei específica que trate do assédio moral, "a interpretação sistemática de nosso ordenamento jurídico autoriza, sem sombra de dúvidas, afirmar a ilicitude do abuso do poder diretivo do empregador em prejuízo da dignidade e da integridade física, moral e psíquica do empregado" (MINISTÉRIO PÚBLICO DO TRABALHO, 2009, p. 40).

\section{Como entender teoricamente o assédio moral?}

As situações retratadas acima - e que são comumente postas como "assédio moral" - mostram que esse fenômeno possui dimensões amplas que extrapolam a esfera subjetiva. Não se trata, obviamente, de negar o lugar da subjetividade em sua compreensão, mas de redimensionar o seu peso e entender como os atos individuais se articulam à organização do trabalho, às políticas empresariais, enfim, ao contexto no

\footnotetext{
${ }^{13}$ Apenas para exemplificar, transcrevemos um dos depoimentos registrados na ACP: "Durante o movimento paredista, a atuação da Empresa [X] foi absolutamente desrespeitosa aos direitos humanos dos trabalhadores. Como o movimento se instaurou dentro das dependências da empresa, o pessoal responsável pela segurança da $[X]$, que tem um passado de alto escalão nos corpos das polícias militares, aplicou táticas policiais para cansar os grevistas. Cortou água, telefone, luz e impediu a entrada de outros trabalhadores. Além disso, suspendeu o funcionamento do restaurante que, em outros dias, funcionava normalmente, impedindo inclusive a entrada de alimentação" (MINISTÉRIO PÚBLICO DO TRABALHO, 2009, p. 5).
} 
qual a atividade se realiza e a forma pela qual ele se articula com a ordem mais geral ditada pela produção de valor. ${ }^{14}$

Em nossa perspectiva, as análises que tomam a "personalidade" como ponto de partida para a compreensão desse fenômeno operam uma inversão ontológica ao pressupor a primazia das características pessoais, consideradas até mesmo de forma independente das relações sociais e da sociabilidade instaurada pela lógica do capital. Nessas abordagens, o indivíduo acaba sendo também o ponto de chegada, uma vez que, ao fundamentarem as explicações na perspectiva individual, esta se torna fonte da degradação das relações interpessoais e também o locus para onde devem se direcionar ações de prevenção ou reparação.

São exemplos típicos desse tipo de análise, as frequentes tentativas de associar o assédio moral a um dado "perfil psicológico" das "vítimas" e dos "assediadores", tendo como origem, conforme já dissemos, os trabalhos pioneiros como os de Hirigoyen (2000; 2002). A personalidade é tratada de forma estática e independente dos modos de sociabilidade e como fonte maior de explicação para toda ação humana, sobretudo quando se trata de atos com forte conteúdo ético. Porém, escapa a esse tipo de análise que a personalidade só pode se constituir a partir de um processo histórico-social e, ao conceber o "resultado/ consequência" como "fonte/causa", ela se desvia de uma explicação razoável e recai em especulações. ${ }^{15}$

Nessa perspectiva, o "assédio moral" parece ganhar vida própria e colocar-se acima das relações materiais e sociais, sendo percebido como uma prática autônoma, independentemente dos sujeitos e da sociabilidade da qual emerge. Ele é que passa a ser visto como origem das relações perversas e do clima negativo que ocorre no ambiente de trabalho, e não as relações características do contexto de trabalho capitalista - com suas contradições e paradoxos - como favorecedoras do assédio ou mesmo responsáveis por torná-lo necessário.

Ao contrário das análises que comumente autonomizam a personalidade, abstraindo-a das condições reais de sua produção, entendemos o assédio moral como o resultado da atividade dos próprios indivíduos, bem como das condições concretas sob as quais produzem e reproduzem suas existências.

Assim, explicar o assédio moral - que é um reflexo da sociabilidade fundada pelo capital - a partir de entidades abstratas e independentes das bases constitutivas da vida social dos indivíduos não nos conduz à raiz do fenômeno, isto é, à sua gênese. Ao contrário, apenas cria falácias em torno do assunto e dificulta a proposição de alternativas concretas de transformação do trabalho e de sua forma de organização para além da própria sociabilidade que serve de base para seu engendramento.

Ao pressupor, por exemplo, que o assédio moral resulta da deliberação clara dos indivíduos, sendo, portanto, fruto exclusivo da vontade pessoal, a tendência é a de se imaginar que a solução do problema passaria pela "boa vontade" e pelo apelo à ética nas relações humanas, como propõe Hirigoyen (2000; 2002):

O assédio se instala quando o diálogo é impossível e a palavra daquele que é agredido não consegue fazer-se ouvir. Prevenir é, portanto, reintroduzir o diálogo e uma comunicação verdadeira. (HIRIGOYEN, 2000, p. 200)

A prevenção passa também pela educação dos responsáveis, ensinando-os a levar em conta a pessoa humana, tanto quanto a produtividade. Em cursos de formação específica, a serem dados por psicólogos ou psiquiatras formados em vitimologia, poder-se-ia ensiná-los a "metacomunicar", isto é, a comunicar sobre a comunicação, a fim de que eles saibam intervir antes que o processo se instale, fazendo dar nome ao que no outro irrita o agressor, fazendo-o "ouvir" o ressentimento de sua vítima. (HIRIGOYEN, 2000, p. 201)

Chefiar os subordinados com respeito pode evitar diversos problemas de mal estar na empresa, o que permite também melhorar a produtividade. Em vez de acrescentar reciclagens destinadas a tornar as pessoas mais produtivas, por que não ousar reintroduzir o componente humano e levar em conta cada indivíduo, com seus traços de personalidade e fragilidades, sem esquecer o componente afetivo ou emotivo das pessoas? (HIRIGOYEN, 2002, p. 316)

Não é difícil imaginar a fragilidade dessas medidas diante das reais causas do problema, uma vez que estas passam muito distante de qualquer

\footnotetext{
${ }^{14}$ Fazemos nossa a recomendação de Erving Goffman (1964), comumente esquecida, de que a análise de interações sociais face a face compreende a análise da própria situação. O contexto de ações sociais não é um mero décor no qual a interação se desenrola, mas determinante essencial da própria interação que, de outra forma, permanece incompreensível (GOFFMAN, 1964).

${ }^{15} \mathrm{O}$ argumento de um gestor, proferido durante uma palestra em uma Semana Interna de Prevenção de Acidentes de Trabalho (SIPAT), ilustra esse viés psicologizante cujas análises se constroem a partir das aparências dos fenômenos, sem chegar às suas raízes. Nas palavras do gestor: “muitas vezes a própria pessoa se isola no contexto de trabalho e assim acaba fazendo o assédio moral acontecer". Não é difícil notar que o argumento utilizado imputa toda a responsabilidade ao próprio indivíduo, e negligencia o fato de que seu isolamento no contexto de trabalho pode ser apenas um sintoma da precariedade das relações interpessoais e do modo de organização do trabalho. Lembremos que o fato de uma pessoa se portar de modo reservado não determina, por si só, o surgimento de conflitos e práticas de violência simbólica reiterada (assédio moral). Em relação a isso, os relatos de alguns trabalhadores chegam a ser bem mais lúcidos, aproximando-se de uma explicação realmente científica, conforme vimos em trecho do depoimento de Ricardo acima reportado: "[...] o que fazia com que as pessoas estavam me isolando era justamente o meu trabalho e não a minha pessoa" (VIEIRA, 2008, p. 93).
} 
voluntarismo. Propor uma terapia da comunicação - acrescentando mais níveis de metacomunicação vai em direção exatamente oposta ao enraizamento das relações intersubjetivas no próprio trabalho e em sua organização. Fica evidente que é somente pela via da abstração e da negação das condições de produção da existência e, consequentemente, das individualidades que se pode caminhar nessa perspectiva, crendo que a resolução de problemas de ordem organizacional e material poderia decorrer da "boa vontade" pessoal, ainda que essa vontade se apresente camuflada por sofisticados processos "metacomunicacionais".

De nada adianta também recorrer ao controle e à punição dos "assediadores", que são apenas o reverso da medalha. Não se trata de transformar assediados em vítimas e assediadores em algozes, mas de reconhecer as condições sociais de produção que os colocam nessas relações antagônicas e instrumentais.

Ao considerar o assédio moral como resultado de atos individuais, determinados por motivos psicológicos, conscientes ou não, Hirigoyen (2002) sugere também que os "diretores de empresas ou instituições públicas" analisem seu "funcionamento inconsciente", o que seria positivo para que não fechassem os olhos para a violência dentro das empresas e continuassem a defender "os escalões superiores acusados de assédio moral” (p. 314).

É verdade que a autora se refere também à necessidade de melhorar as condições de trabalho e à prevenção do estresse como medidas que poderiam evitar o assédio moral. Tal proposta, no entanto, contradiz suas próprias análises ao afirmar que o estresse e as condições de trabalho não constituem os fatores que realmente determinam o assédio moral, conforme citado anteriormente. É claro que os indivíduos podem se beneficiar de processos psicoterápicos, mas isso seria suficiente para combater o assédio moral ou mesmo a sociabilidade degradante do capital que o enseja?

No âmbito administrativo, a autora, entendendo que o problema do assédio moral é "antes de tudo o dos limites e da regra", recomenda que os chefes se afirmem para restaurar a ordem, "detectando comportamentos inadequados e depois aplicando punições, quando necessário” (p. 319). Essa sugestão pressupõe que a clareza e a consciência das regras e dos limites organizacionais, bem como a punição dos assediadores, seriam suficientes para evitar o assédio moral, como se, novamente, esse fenômeno se reduzisse a uma deterioração da moral individual ou da "falta de consciência" e "respeito".

Por tudo isso, torna-se necessário operar uma inversão na discussão que tem sido promovida a respeito do assédio moral e que conquistou espaço nos meios empresariais, o que talvez se explique justamente pela impotência desse discurso para refundar uma nova ordem das coisas. Ao contrário das abordagens centradas na personalidade, é relevante considerar as raízes "ontogenéticas" da individualidade, síntese dos modos de sociabilidade (CHASIN, 2001; 2009). O indivíduo, que se quer livre e dotado de vontade, é, de fato, a individualidade contingente que encima um longo processo histórico de dissolução de relações comunitárias (MARX, 2011). A liberdade abstrata do indivíduo moderno é também sua cadeia, pois, para sobreviver, precisa, antes, tornar-se trabalhador, condição sempre provisória, porque é ameaçada pela demissão. Por outro lado, a vontade dos chefes assediadores expressa a posição, também alienada, das pessoas investidas do poder do capital.

Tadavia, cabe ressaltar que não se trata aqui de "sociologizar" o assédio moral, mas sim de levar a discussão a suas raízes, considerando, de forma articulada, as mediações que viabilizam o surgimento de certas violências nos contextos de trabalho, a saber: as políticas empresariais, os modelos de gestão, os modos de organização do trabalho e, evidentemente, os aspectos subjetivos e interpessoais. O egoísmo, o individualismo, a intolerância e o utilitarismo que impregnam as relações de trabalho não derivam de invariantes universais da personalidade humana; parece ser mais adequado tratá-los como valores próprios à sociabilidade do capital, à qual não se pode deixar de interrogar quando se trata do "assédio moral". Diferentemente das sociedades pré-capitalistas (MARX, 2011), a determinação essencial do indivíduo moderno é sua contingência, sua existência separada das condições objetivas de reprodução de sua vida e seu isolamento social.

A concorrência isola os indivíduos uns dos outros, não apenas os burgueses, mas ainda mais os proletários, apesar de agregá-los. Por isso, transcorre sempre um longo período antes que os indivíduos possam se unir (...); todo poder organizado em face desses indivíduos que vivem isolados e em relações que diariamente reproduzem o isolamento só pode ser vencido após longas lutas. Exigir o contrário seria o mesmo que exigir que a concorrência não deva existir nessa época histórica determinada ou que os indivíduos devam apagar de suas mentes relações sobre as quais não têm nenhum controle como indivíduos isolados. (MARX; ENGELS, 2007, p. 62)

Nessas condições, o tecido social é constituído por relações instrumentais, em que o outro não é um fim, mas um simples meio para objetivos estranhos aos próprios indivíduos: a produção se torna um fim em si mesmo. A imoralidade das relações interpessoais no trabalho, a intolerância com os erros e o mau desempenho não nascem de características de personalidade, mas das necessidades da concorrência intercapitalista. Por que, mesmo admitindo que errar é humano, vou manter um trabalhador com de- 
sempenho inferior quando tenho que escolher quem demitir? Se um trabalhador se mostra mais cooperativo, porque não reconhecer este "colaborador" nas promoções e preterir aquele que causa dificuldades, que não coopera? ${ }^{16}$ As arbitrariedades dos pequenos chefes na distribuição de benesses e castigos informais (as "perseguições" sempre citadas nos casos de assédio) refletem as estratégias instrumentais para vencer a resistência dos trabalhadores que, por uma razão ou outra, criam obstáculos ao bom andamento da produção. Como de fato não é nem mesmo a produção por si mesma que importa, mas a reprodução ampliada do valor, a melhoria de desempenho tem que ser contínua, sem descanso; a meta alcançada em um ano é apenas o ponto de partida para a meta do ano seguinte e assim por diante, até que a capacidade ou a disponibilidade do trabalhador (que pode, por exemplo, ter a infeliz ideia de pensar em ter uma vida pessoal) cheguem a um limite. É quando sua serventia cessa que começa a surgir o assédio moral.

Portanto, em nosso entendimento, o assédio moral é o reflexo de uma sociabilidade degradada e moralmente degradante instaurada pela lógica do valor. Isso quer dizer que, em um mesmo modo de produção com suas determinações gerais, podem existir formas de sociabilidade mais ou menos degradadas com efeitos morais diferenciados. $\mathrm{O}$ capitalismo pretende separar as esferas da vida e criar uma economia amoral, regida apenas pelas leis de mercado e pelo egoísmo racional. No entanto, a economia fundada da produção do valor secreta sua própria moral que os economistas que se dizem moralmente indiferentes acabam por expressar:

Por isso, ela [a economia política] é - apesar de seu aspecto mundano e voluptuoso - uma ciência efetivamente moral, a mais moral de todas as ciências. A auto-renúncia, a renúncia à vida, a todas as carências humanas, é a sua tese principal. Quanto menos comeres, beberes, comprares livros, fores ao teatro, ao baile, ao restaurante, pensares, amares, teorizares, cantares, pintares, esgrimires etc., tanto mais tu poupas, tanto maior se tornará o teu tesouro, que nem traças nem o roubo corroem, teu capital. Quanto menos tu fores, quanto menos externares a tua vida, tanto mais tens, tanto maior é a tua vida exterioriza$d a$, tanto mais acumulas de tua essência estranhada. (MARX, 2004, p. 141-142)

Enquanto fenômeno aparente, o assédio moral encontra suas raízes em um modo específico de organização do trabalho, no qual a implicação subjetiva dos trabalhadores, doravante denominados "colaboradores", é uma importante fonte de eficiência e de valorização do capital. Convém, então, apontar o equívoco em se abordar as relações sociais no contexto de tra- balho sem considerar que elas são matrizadas pela lei do valor e pelo modo de sociabilidade imposto pelo capital. Todavia, essa afirmação de validade geral, et pour cause, não isenta qualquer pesquisador da tarefa de demonstrar, em cada caso particular, de que modo essa lógica se efetiva nas situações reais de trabalho e por que mediações ela conduz aos conflitos. Pois, entre a lei do valor instaurada pelo capital e a ocorrência do assédio moral, tem-se um conjunto de mediações que aparece nos casos concretos, conforme nos esforçamos em demonstrar acima com exemplos do trabalho dos vigilantes. Em cada uma das imposições e exigências absurdas impostas pelos gestores a esses trabalhadores, subentende-se uma finalidade que lhes é estranha, mas perfeitamente compreensível na perspectiva da acumulação capitalista. A dilatação constante e excessiva da jornada de trabalho, as exigências de tarefas extras e em tempo exíguo, as rígidas regras de segurança que, no jogo de poder entre seguradoras, bancos e prestadoras de serviço de vigilância, colocam em conflito vigilantes, bancários e clientes, são exemplos práticos de como essas mediações se materializam.

\section{Considerações finais}

Ao adotar como ponto de partida o trabalho concreto, tentamos expor os perigos de se cair em vieses comuns nas discussões em torno do problema do assédio moral, sendo os mais recorrentes a psicologização, a judicialização e a sociologização, quando apenas um fator é privilegiado em detrimento de outros que também fazem parte desse complexo problema.

No caso da psicologização, talvez o mais frequente e o mais grave entre esses três vieses, privilegiam-se os fatores de personalidade ou até mesmo nos colocam como os únicos determinantes do problema. Isso é particularmente visível em algumas definições dadas ao assédio moral, sobretudo quando se atribui uma intencionalidade ao agressor em atingir psicologicamente a vítima, como uma espécie de sadismo, de prazer em ver o outro sofrer. No entanto, sem desconsiderar a possibilidade de que existam pessoas realmente sádicas (e perversas) nesse contexto, não podemos nos esquecer de que esses atos ocorrem quase sempre em um ambiente de trabalho no qual o próprio "assediador" também está sujeito a exigências absurdas de produtividade. Nesses casos, poderíamos pensar que seus atos podem decorrer muito mais do seu esforço em responder a essas exigências do que de seu desejo inconsciente ou vontade expressa de humilhar o outro.

\footnotetext{
${ }^{16}$ Alguém imaginaria que o termo "colaborador" pelo qual se designa o assalariado nas empresas contemporâneas surgiu por acaso? Seu uso generalizado é o contraponto do assédio aos não colaboradores.
} 
Nessas análises ocorre uma descontextualização desses atos, ou seja, as ações do "assediador" são desvinculadas das situações concretas em que são praticadas, mas cabe ressaltar também que não se pretende, aqui, isentar o agressor da responsabilidade por seus atos, inclusive no plano jurídico, mas apenas sugerir que estes podem ter um significado que vai além do prazer imoral de humilhar alguém.

Em suma, essa visão parcial do problema termina por camuflar a situação real de trabalho, com todas as pressões que esta exerce sobre cada indivíduo em particular, ou, na melhor das hipóteses, por colocá-la como pano de fundo do cenário no qual se desenrola o drama do assédio moral. Ou seja, mesmo quando esse contexto é considerado, aparece apenas como mais um elemento que compõe a cena, sem que fique clara sua real importância.

A perspectiva do trabalho nos leva em outra direção. A compreensão do assédio moral deveria ser buscada a partir da articulação entre as características pessoais dos sujeitos em conflito e os aspectos concretos do seu trabalho: as políticas da empresa, a forma como esta se situa no mercado, as contradições organizacionais, as exigências que impõe aos seus empregados, os impactos psíquicos dessas exigências.

Essa articulação se mostra essencial, sobretudo quando se percebe, em alguns casos analisados, a existência de empresas que valorizam e até premiam aqueles que adotam comportamentos agressivos, oferecendo-lhes cargos de chefia. Por que, então, surpreender-se com os atos de assédio moral, quando os critérios de ascensão profissional valorizam o estilo do empreendedor agressivo? Por meio dessas práti- cas, as empresas não apenas toleram, mas incentivam esses comportamentos, e aqueles que quiserem prosseguir em seus projetos de carreira terão que se dispor a isso. Esse dilema não é novo, apenas adquire novas cores nas empresas hipermodernas. Alguns trabalhadores preferem não se tornar chefes porque conhecem as regras do jogo do qual não querem fazer parte (BERNOUX, 1981). Como é sabido, Taylor fundou a “organização científica do trabalho" precisamente quando assumiu o outro lado - o da hierarquia.

Dessa forma, sem querer isentar os que praticam o assédio moral da responsabilidade pelos seus atos, não podemos negligenciar que tais atos ocorrem em um contexto no qual são valorizados, incentivados e até mesmo exigidos. Isso significa que a empresa, suas políticas e a forma pela qual o trabalho é organizado não compõem apenas um “cenário” no qual se desenrola o drama do assédio moral, mas são partes constitutivas do problema, na verdade, seus determinantes essenciais.

Em suma, no nosso entender, o assédio moral deveria ser apreendido a partir de uma perspectiva mais ampla que considera desde o contexto econômico e político, de modo geral, até o contexto organizacional e do trabalho, passando, evidentemente, pela singularidade dos seus protagonistas. A única forma de compreendê-lo na sua efetividade e determinação é analisando a forma pela qual essas dimensões interagem e se interpenetram dinamicamente, reconhecendo suas importâncias relativas. Esse parece ser o melhor caminho para se alcançar um avanço efetivo. Afinal, sem compreender devidamente um problema, como encontrar a melhor maneira de atacá-lo?

\section{Contribuições de autoria}

Todos os autores participaram das pesquisas de campo de onde foi retirado o material empírico deste artigo, sendo que o caso do vigilante Ricardo é resultado de pesquisa própria de Carlos Eduardo Carrusca Vieira. Todos os autores contribuíram para a revisão bibliográfica, cada um em sua especialidade, e análise crítica das principais referências sobre assédio moral, assim como na redação original e nas diferentes revisões do texto após avaliação dos pareceristas.

\section{Referências}

AGUIAR, A. L. S. Assédio moral: o direito à indenização pelos maus tratos e humilhações sofridos no ambiente de trabalho. São Paulo: LTr, 2006.

BARRETO, M. M. S. Violência, saúde, trabalho: uma jornada de humilhações. São Paulo: Educ; Fapesp, 2003.

BERNOUX, P. Un travail à soi. Toulouse: Éd. Privat, 1981.

BRASIL. Lei no 6.321, de 14 de abril de 1976. Dispõe sobre a dedução, do lucro tributável para fins de imposto sobre a renda das pessoas jurídicas, do dobro das despesas realizadas em programas de alimentação do trabalhador. Disponível em: < http://www.jusbrasil. com.br/legislacao/104849/lei-6321-76 > . Acesso em: 20 abr. 2011.

. Lei no 7.783 , de 28 de junho de 1989. Dispõe sobre o exercício do direito de greve, define as atividades essenciais, regula o atendimento das necessidades inadiáveis da comunidade, e dá outras 
providências. Disponível em: < http://www.planalto.gov. br/ccivil/leis/L778203.htm>. Acesso em: 20 abr. 2011.

Portaria n⿳o 03, de 1o de março de 2002.

Baixa instruções sobre a execução do Programa de Alimentação do Trabalhador (PAT). Disponível em: <http://www.mte.gov.br/legislacao/portarias/2002/ p_20020301_03.pdf >. Acesso em: 20 abr. 2011.

CHASIN, J. Marx: estatuto ontológico e resolução metodológica. São Paulo: Boitempo, 2009.

. Rota e prospectiva de um projeto marxista.

Ensaios Ad Hominem. São Paulo, Tomo IV, n. 1 Dossiê Marx, p. 7-78, 2001.

CLOT, Y. Travail et Santé. Revue Psycho Media, n. 2, jan/fev. 2005.

FREITAS, M. E. de. Assédio moral e assédio sexual: faces do poder perverso nas organizações. Revista de Administração de Empresas, São Paulo, v. 41, n. 2, p. 8-19, abr/jun. 2001.

FREITAS, M. E. de; HELOANI, R.; BARRETO, M. Assédio moral no trabalho. São Paulo: Cengage, 2008.

FRONTZEK, L. G. M. Assédio moral: novos rumos da violência psicológica no trabalho. 2009. $99 \mathrm{f}$. Dissertação (Mestrado em Psicologia)-Faculdade de Filosofia e Ciências Humanas, Universidade Federal de Minas Gerais, Belo Horizonte, 2009.

GAULEJAC, V. de. Gestão como doença social: ideologia, poder gerencialista e fragmentação social. São Paulo: Idéias e Letras, 2007.

GOFFMAN, E. The neglected situation. American anthropologist, v. 66, n. 2, p. 133-136, dez. 1964.

GUEDES, M. N. G. Terror psicológico no trabalho. São Paulo: LTr, 2003.

GUIMARÃES, L. A. M.; RIMOLI, A. O. "Mobbing" (assédio psicológico) no trabalho: uma síndrome psicossocial multidimensional. Psicologia: teoria e pesquisa, v. 22, p. 183-192, maio/ago. 2006.

HIRIGOYEN, M.-F. Assédio moral: a violência perversa do cotidiano. São Paulo: Bertrand do Brasil, 2000.

. Mal-estar no trabalho: redefinindo o assédio moral. São Paulo: Bertrand do Brasil, 2002.

HIRIGOYEN, M.-F.; ASKENAZY, P.; CLOT, Y. Débat: Travail et santé. Psychomédia, n. 2, p. 7-15, jan./fev. 2005.

LEYMANN, H. Mobbing and psychological terror at workplaces. Violence and victims, v. 5, n. 2, p. 119126, 1990.
Seuil. 1993.

. Mobbing: la persécution au travail. Paris:

. Contenido y desarrollo del acoso grupal/moral ("Mobbing") en el trabajo. European Journal of Work and Organizational Psychology, v. 5, n. 2, p. 165-184, 1996.

LUKÁCS, G. Prolegômenos para uma ontologia do ser social. São Paulo: Boitempo, 2010.

MINISTÉRIO PÚBLICO DO TRABALHO. Processo

n. 995-2009-106-03-00-5. Belo Horizonte: Ministério Público do Trabalho, 2009.

MARX, K. Formações econômicas pré-capitalistas. Rio de Janeiro: Paz e Terra, 1985.

. Grundrisse. São Paulo: Boitempo; Rio de

Janeiro: EDUFRJ, 2011.

. Manuscritos econômico-filosóficos. São Paulo:

Boitempo, 2004.

MARX, K.; ENGELS, F. A ideologia alemã. São Paulo: Boitempo, 2007.

SOBOLL, L. A. P. Assédio moral/organizacional: uma análise da organização do trabalho. São Paulo: Casa do Psicólogo, 2008.

TEIXEIRA, R. Assédio moral nas organizações. Disponível em: < http://www.assediomoral. net/publicacoes/Assedio\%20Moral\%20nas\%20 Organizacoes\%20(Rodilon\%20Teixeira).pdf $>$. Acesso em: 30 abr. 2011.

TROMBETA, T.; ZANELLI, J. C. Características do assédio moral. Curitiba: Juruá, 2010.

VIEIRA, C. E. C. Assédio: do moral ao psicossocial desvendando os enigmas da organização do trabalho. Curitiba: Juruá, 2008.

O nexo causal entre o transtorno de estresse pós-traumático e trabalho: controvérsias acerca do laudo de uma perícia judicial. Revista Brasileira de Saúde Ocupacional, v. 34, p. 150-162, 2009.

VIEIRA, C. E. C.; LIMA, F. de P. A.; LIMA, M. E. A. (Orgs.). O cotidiano dos vigilantes: trabalho, saúde e adoecimento. Belo Horizonte: Fumarc, 2010.

ZIMMERMANN, S. M.; SANTOS, T. C. D. R. dos; LIMA, W. C. M. de. O assédio moral e o mundo do trabalho. Disponível em: <http://www.prt12.mpt.gov. br/prt/ambiente/arquivos/assedio_moral_texto.pdf $>$. Acesso em: 30 abr. 2011. 